\title{
AMMI Stability Analysis and Estimation of Genetic Parameters for Growth and Yield Components in Cassava in the Forest and Guinea Savannah Ecologies of Ghana
}

\author{
Joseph Adjebeng-Danquah, ${ }^{1}$ Joseph Manu-Aduening, ${ }^{2}$ Vernon Edward Gracen,, \\ Isaac Kwadwo Asante, ${ }^{4}$ and Samuel Kwame Offei ${ }^{4}$ \\ ${ }^{1}$ CSIR-Savanna Agricultural Research Institute, P.O. Box TL 52, Tamale, Ghana \\ ${ }^{2}$ CSIR-Crops Research Institute, P.O. Box 3785, Kumasi, Ghana \\ ${ }^{3}$ Cornell University, Ithaca, NY, USA \\ ${ }^{4}$ West Africa Centre Crop Improvement (WACCI), University of Ghana, Legon, Ghana
}

Correspondence should be addressed to Joseph Adjebeng-Danquah; barchus2003@yahoo.com

Received 13 March 2017; Accepted 12 June 2017; Published 13 July 2017

Academic Editor: Kent Burkey

Copyright (C) 2017 Joseph Adjebeng-Danquah et al. This is an open access article distributed under the Creative Commons Attribution License, which permits unrestricted use, distribution, and reproduction in any medium, provided the original work is properly cited.

\begin{abstract}
Twenty cassava genotypes were arranged in a randomised complete block design with three replications and assessed for growth and yield stability using the additive main effect and multiplicative interaction (AMMI) analysis. Highly significant $(P<0.001)$ effects of genotype, environment, and genotype * environment interaction were observed for all traits studied. The AMMI analysis of variance indicated that genotype accounted for $51 \%$ of the total sum of squares for height at first branching followed by environment (33\%) and interaction (15\%). For fresh root yield, environment effects accounted for $37 \%$ of the total sum of squares, whilst genotype and interaction accounted for $32 \%$ and $29 \%$, respectively. Genotypic variances for harvest index (HI), plant height, storage root yield, and dry matter content contributed a greater proportion of the phenotypic variance indicating stronger genetic control. This suggests better chance of progress in the genetic improvement of these traits. Genotype MM96/1751 combined high yield with stability according to the yield stability index ranking across environments. On the other hand genotypes UCC 2001/449 and 96/1708 though high yielding were unstable according to AMMI stability value scores. However they can be tested further in more environments to ascertain their specific adaptability for release to farmers for cultivation to boost cassava production and ensure food security.
\end{abstract}

\section{Introduction}

Cassava (Manihot esculenta Crantz) is grown in a wide range of environments but severe yield losses occur in traditional cultivars grown by poor farmers [1-3]. Root yield losses in poor drought-prone environments can be as high as $80 \%$ when compared with root yield in optimum environments [4]. This is because genotypes exhibit different levels of phenotypic expression under different environmental conditions resulting in crossover performances [5]. Crossover performances by genotypes in different environments result from differential responses under varying environmental conditions $[6,7]$. This was defined as genotype $*$ environment
$(G * E)$ interaction [8]. Studies on cassava's performance in different environments have indicated significant $G * E$ effect for root yield and yield components [9-12].

Genotype * environment interaction also results from differences in the sensitivities of genotypes to the conditions in the target environment [13] leading to inconsistent performances of genotypes across environments. This limits the efficiency of selection of superior genotypes [14]. In $G * E$ interaction, the magnitude of the observed genetic variances changes from one environment to the next and tends to be larger in better environments than poorer environments [15]. Breeding cassava for yield involves different attributes of genotypes that are subject to influences by variation in 
environmental conditions [16]. The objective of most cassava yield improvement programmes is to identify and select high yielding and stable genotypes across several environments and seasons [11]. The efficiency and success of such selection depend on the consistency of performances of genotypes in varying environments [17]. For this reason, genotypes are tested in diverse environments to assess their adaptability and stability [5]. Genotypes whose $G * E$ effects are not significant are said to be stable [14].

Several methods have been used to assess the $G *$ $E$ effect and stability in crop performances. Eberhart and Russell [18] proposed joint regression analysis to estimate the average performance of a genotype in different environments relative to the mean performance of all genotypes in the same environment. Multiplicative models which include the additive main effect and multiplicative interaction (AMMI) model have also been used $[19,20]$. The AMMI model fits the sum of several multiplicative terms rather than only one multiplicative term in assessing the performance of genotypes in different environments [21]. AMMI analysis can be used to determine stability of the genotypes across locations using the PCA (principal component axis) scores and AMMI stability value (ASV) [22]. The ASV is based on the AMMI model's IPCA1 and IPCA2 (interaction principal components axes 1 and 2, resp.) scores for each genotype [23]. Genotypes having the least ASV are considered as widely adapted genotypes. Similarly, IPCA2 score near zero indicates more stable genotypes whilst large values represent more responsive and less stable genotypes.

Stability per se does not give much information about the level of yield so Farshadfar et al. [24] and Tumuhimbise et al. [25] used yield stability index (YSI) and genotype stability index (GSI) which combined high yield performance with stability. Both the YSI and the GSI are based on the sum of the ranking due to ASV scores and yield or performance ranking. Lower YSI and GSI values indicate genotypes that combine high yield or performance with stability [24, 26, 27]. The study was conducted to assess the performance and stability of cassava genotypes for fresh root yield and other yield components. Specific objectives were to identify high yielding stable cassava genotypes and estimate the variance components as well as broad sense heritability of root yield and other traits.

\section{Materials and Methods}

The experiments were conducted during the 2012/2013 and 2013/2014 growing seasons. The trials were conducted at the research fields of the CSIR-Savanna Agricultural Research Institute located at Nyankpala $\left(9^{\circ} 25^{\prime} \mathrm{N}, 0^{\circ} 58^{\prime} \mathrm{W}\right)$ in the Guinea Savannah Agroecological Zone and the Crops Research Institute located at Fumesua $\left(6^{\circ} 41 \mathrm{~N} 1^{\circ} 28 \mathrm{~W}\right)$ in the Forest Agroecological Zone of Ghana. The Guinea Savannah Zone which covers over $40 \%$ of the land area of Ghana is characterised by high temperatures and low humidity for most parts of the year [28]. The rainfall pattern is monomodal and erratic with an annual mean of $1100 \mathrm{~mm}$. The rains usually begin in April-May, end in October, and are followed by a long dry season (5-7 months) which normally begins in
TABLE 1: List of cassava genotypes used in the study.

\begin{tabular}{lccc}
\hline Genotype & Source & Genotype & Source \\
\hline ATR 002 & Local & $00 / 0203$ & IITA \\
ATR 007 & Local & $96 / 1708$ & IITA \\
NWA 004 & Local & I91934 & IITA \\
Pontisange* $_{\text {Biabasse }}^{*}$ & Local & CTSIA 45 & CIAT \\
UCC2001/449 & Local & CTSIA 48 & CIAT \\
TME 419 & Local & CTSIA 65 & CIAT \\
TME 435 & IITA & CTSIA 72 & CIAT \\
96/409 & IITA & CTSIA 112 & CIAT \\
MM96/1751 & IITA & CTSIA 230 & CIAT \\
\hline
\end{tabular}

Local $=$ genotypes from local sources, IITA $=$ genotypes obtained from the International Institute for Tropical Agriculture, and CIAT = genotypes obtained from the International Center for Tropical Agriculture. ${ }^{*}$ Local farmer preferred varieties.

November and lasts till April. Intermittent dry spells usually occur even during the rainy season. This experimental site represented the low potential environment.

The site at the CSIR-Crops Research Institute (CSIRCRI) was located at Fumesua within the Forest Agroecology which is characterised by a bimodal rainfall pattern, major and minor rainy seasons. The major rainy season begins in February and ends in August and then is followed by the minor season which begins in September and ends in November. This site represented the high potential environment for assessing the genotypes for high yield potential.

Twenty cassava genotypes were used for the experiment (Table 1). These included six local landraces collected from farmers' fields, seven drought tolerant genotypes obtained from the International Institute of Tropical Agriculture (IITA), Nigeria, and seven genotypes from the International Center for Tropical Agriculture (CIAT), Columbia. The genotypes were arranged in a randomised complete block design with three replications under each growing condition. A plot consisted of four rows with ten plants in a row giving a population of 40 plants in each plot.

At each site the land was ploughed, harrowed, and laid out in a randomised complete block with three replications. Ridges were manually raised for the trials at CSIR-SARI, Nyankpala, but planting was done on the flat at Fumesua based on the regular practice. The 20 cassava genotypes represent the treatments. Each plot was made up of four rows with 10 plants in a row. Mature cassava cuttings measuring $25-30 \mathrm{~cm}$ were planted using a spacing of $1 \mathrm{~m} \times 1 \mathrm{~m}$ on the top of ridge or flat as the case may be at an angle of $45^{\circ}$ to the ground surface [29]. No fertilizer was applied to the trials but weeds were manually controlled using cutlasses and hoes as and when necessary.

Monthly data were recorded on growth parameters including plant height $(\mathrm{cm})$, stem girth $(\mathrm{cm})$, and plant height at first branching $(\mathrm{cm})$ which were collected at three months after planting and continued till harvest at 12 months. Harvesting was done at 12 months after planting. Eight plants from the two inner rows were sampled for yield 
determination. Storage root yield was estimated per plot and extrapolated to tons per hectare. For storage root dry matter content determination, roots were first chopped into pieces (about $1 \mathrm{~cm}$ thick) and mixed thoroughly. Afterwards three $100 \mathrm{~g}$ subsamples were taken and oven-dried at $80^{\circ} \mathrm{C}$ for 48 hours and weighed. Dry matter content for each sample was obtained by expressing the dry weight as a percentage of the original fresh weight of the sample taken. An average of the three samples was calculated to obtain the dry matter content of the respective genotypes. Cassava mosaic disease (CMD) severity was scored using a scale of 1-5 where 1 denotes no symptom and 5 denotes highly diseased plants [30].

The data were subjected to analysis of variance using GenStat software version 12.1 [31] to determine the significance of the main effects and interactions. Combined analysis of all growth parameters as well as root yield and yield components from the different growing environments was done. Two growing environments (Nyankpala and Fumesua) and two growing seasons (2013 and 2014) were used.

Variance components (genotypic, phenotypic, and environment as well as genotype $*$ environment variances) were also estimated from their respective mean squares obtained from the analysis of variance table according to Ntawuruhunga and Dixon [16]. Broad sense heritability $\left(\mathrm{H}^{2}{ }_{b}\right)$ was estimated according to Padi [32] as follows:

$$
\begin{aligned}
H^{2} & =\frac{\sigma_{g}^{2}}{\sigma_{p}^{2}}, \\
\sigma_{p}^{2} & =\left(\sigma_{g}^{2}\right)+\left(\frac{\sigma_{g * e}^{2}}{E}\right)+\left(\frac{\sigma_{e}^{2}}{E R}\right),
\end{aligned}
$$

where

$$
\begin{aligned}
& \sigma_{g}^{2} \text { is genotypic variance; } \\
& \sigma_{p}^{2} \text { is phenotypic variance; } \\
& \sigma^{2}{ }_{g * e} \text { is genotype } * \text { environment variance; } \\
& \sigma_{e}^{2} \text { is pooled error; }
\end{aligned}
$$

$E$ is number of environments;

$R$ is number of replications.

Genotypic coefficient of variation (GCV) and phenotypic coefficient of variation (PCV) were estimated according to Singh and Chaudhary [33] as follows:

$$
\begin{aligned}
& \operatorname{GCV}(\%)=\left(\frac{\sqrt{ } \sigma_{g}^{2}}{\ddot{X}}\right) * 100 \%, \\
& \operatorname{PCV}(\%)=\left(\frac{\sqrt{ } \sigma_{p}^{2}}{\ddot{X}}\right) * 100 \%,
\end{aligned}
$$

where $\ddot{X}$ is grand mean.

Expected genetic advance, GA, was calculated as

$$
\mathrm{GA}=(K) \sigma_{A} H^{2},
$$

where GA is expected genetic advance.
$K$ is Selection differential (2.06 at $5 \%$ selection intensity).

$\sigma_{A}$ is phenotypic standard deviation.

Genetic advance as a percentage of mean (GAM) was also estimated using the following formula:

$$
\mathrm{GAM}=\frac{\mathrm{GA}}{\ddot{X}} * 100 .
$$

2.1. Stability Analysis. Additive main effect and multiplicative interaction (AMMI) model in GenStat 12.1 [31] was used to determine the stability of the genotypes across environments. The AMMI model first fits the additive effects for the genotypes and the growing environments (two growing environments and two seasons) and multiplicative term for genotype $*$ environment interactions.

The AMMI model according to Farshadfar et al. [24] is presented as

$$
Y_{i j}=\mu+g_{i}+e_{j}+\sum_{k=1}^{n} \lambda_{k} \alpha_{i k} \gamma_{j k}+e_{i j}
$$

where $Y_{i j}$ is the yield of the $i$ th genotype in the $j$ th environment, $g_{i}$ is the mean of the $i$ th genotype minus the grand mean, $\lambda_{k}$ is the square root of the eigenvalue of the PCA axis $k, \alpha_{i k}$ and $\gamma_{j k}$ are the principal component scores for PCA axis $k$ of the $i$ th genotype and the $j$ th environment, respectively, and $e_{i j}$ is the residual. The environment and genotypic PCA scores are expressed as unit vector times the square root of $\lambda_{k}$; i.e., environment PCA score $=\lambda_{k}{ }^{0.5} Y_{i k} ; 0.5$; genotype PCA score $=\lambda_{k}^{0.5} \alpha_{i k}$.

AMMI stability value (ASV) was calculated for each genotype according to the relative contributions of the principal component axis scores (IPCA1 and IPCA2) to the interaction sum of squares.

The AMMI stability value (ASV) as described by Purchase et al. [23] was calculated as follows:

$$
=\sqrt{\left[\frac{\text { IPCA } \left.1_{\text {Sum of squares }}\left(I P C A 2_{\text {score }}\right)\right]^{2}+\left(I P C A 2_{\text {score }}\right)^{2}}{\text { IPC squares }},\right.},
$$

where IPCA $1_{\text {Sum of squares }} / \mathrm{IPCA} 2_{\text {Sum of squares }}$ is the weight given to the IPCA1-value by dividing the IPCA1 sum of squares (from the AMMI analysis of variance table) by the IPCA2 sum of squares. The larger the IPCA score is, either negative or positive, the more adapted a genotype is to a certain environment. Smaller ASV scores indicate a more stable genotype across environments [24].

Yield stability index was also calculated using the sum of the ranking based on yield and ranking based on the AMMI stability value.

$$
\mathrm{YSI}=\mathrm{RASV}+\mathrm{RY}
$$

where 
TABLE 2: Total rainfall, mean temperature, and average relative humidity during the period of the experiment.

\begin{tabular}{lccc}
\hline Environment & Total rainfall $(\mathrm{mm})$ & Mean temperature $\left({ }^{\circ} \mathrm{C}\right)$ & Relative humidity $(\%)$ \\
\hline Nyankpala 2013 & 991.68 & 28.29 & 68.68 \\
Nyankpala 2014 & 1181.04 & 28.71 & 68.5 \\
Fumesua 2013 & 1147.08 & 27.3 & 75.4 \\
Fumesua 2014 & 1620 & 25.8 & 81.3 \\
\hline
\end{tabular}

TABLE 3: Combined analyses of variance for seven traits evaluated on 20 cassava genotypes in two ecologies of Ghana.

\begin{tabular}{|c|c|c|c|c|c|c|c|c|}
\hline Source & $\mathrm{df}$ & Plt_ht $(\mathrm{cm})$ & Stem diam $(\mathrm{cm})$ & Ht_branch & Rt_yld (t/ha) & DM\% & $\mathrm{HI}$ & CMD score \\
\hline Rep & 2 & 741.60 & 0.74 & 1739.90 & 178.22 & 11.20 & 0.02 & 0.84 \\
\hline Geno (G) & 19 & $9548.50^{* * *}$ & $0.46^{* * *}$ & $9375.50^{* * *}$ & $604.61^{* * *}$ & $91.87^{* * *}$ & $0.05^{* * *}$ & $7.07^{* * *}$ \\
\hline Env $(\mathrm{E})$ & 3 & $298047.90^{* * *}$ & $2.77^{* * *}$ & $39224.30^{* * *}$ & $4385.50^{* * *}$ & $105.56^{* * *}$ & $0.16^{* * *}$ & $17.57^{* * *}$ \\
\hline$G * E$ & 57 & $1376.30^{* *}$ & $0.18^{* * *}$ & $993.50^{* * *}$ & $182.23^{* * *}$ & $20.47^{*}$ & $0.03^{* * *}$ & $1.08^{* * *}$ \\
\hline Residual & 158 & 750.70 & 0.09 & 481.50 & 61.58 & 13.95 & 0.01 & 0.22 \\
\hline
\end{tabular}

Total 239

$*, * *, * * *=$ significant at $P<0.05, P<0.01$, and $P<0.001$, respectively, ns $=$ not significant $(P>0.05)$, $\mathrm{df}=$ degree of freedom, Plt_ht $=$ plant height $(\mathrm{cm})$, Stem diam = stem diameter $(\mathrm{cm})$, Ht_branch $=$ height at first branching $(\mathrm{cm})$, Rt_yld $=$ storage root yield $(\mathrm{t} / \mathrm{ha}), \mathrm{DM} \%=$ dry matter content $(\%)$, HI $=$ harvest index, and CMD_Score (1-5) = cassava mosaic disease score (based on scoring chart where 1 denotes no symptom and 5 denotes highly diseased plants).

RASV is the rank of the genotypes based on the AMMI stability value;

$\mathrm{RY}$ is the rank of the genotypes based on yield across environments (RY).

YSI incorporates both mean yield and stability in a single criterion. Low values of both parameters show desirable genotypes with high mean yield and stability $[25,34]$.

\section{Results}

The environments differed in total rainfall amounts, mean temperature, and relative humidity (Table 2). The total rainfall recorded in 2014 was higher than that recorded in 2013 for both locations. For Fumesua in 2014, $1620.00 \mathrm{~mm}$ was recorded which was higher than in 2013 (1147.08 mm). Higher amount of rainfall was also recorded at Nyankpala in 2014 $(1181.04 \mathrm{~mm})$ than Nyankpala in 2013 (991.68 mm). Mean monthly temperature recordings at Nyankpala were higher than at Fumesua in both years. The environments at Fumesua (FUM13; 75.4\% and FUM14; 81.3\%) also had higher relative humidity than Nyankpala in both years (Nyank2013; 68.68\% and Nyank2014; 68.5\%).

There were highly significant $(P<0.001)$ effect of genotypes and environment for all the traits studied (Table 3 ). Genotype * environment effect was significant $(P<0.05)$ for storage root dry matter content, very significant $(P<0.01)$ for plant height, and highly significant $(P<0.001)$ for stem diameter, plant height at first branching, storage root yield, harvest index, and cassava mosaic disease score.

The AMMI analysis of variance indicated highly significant $(P<0.001)$ effects of genotype, environment, and interaction for all traits (Table 4). Genotypic factors accounted for larger proportion of the treatment sum of squares for plant height at first branching, dry matter content, harvest index, and cassava mosaic disease score environment and genotype * environment interactions. Genotype effect accounted for $15.72 \%$ of the treatment sum of squares (SS) for plant height $(\mathrm{cm})$ whilst environment and interaction accounted for $77.48 \%$ and $6.80 \%$, respectively. The first two interaction principal component axes (IPCA1 and IPCA2) accounted for $85.10 \%$ of the interaction sum of squares. For stem diameter, $32.10 \%$ of the treatment sum of squares was due to genotype effect whilst environment and interaction effect accounted for $30.38 \%$ and $37.52 \%$, respectively. The IPCA1 accounted for $74.63 \%$ with IPCA2 accounting for $13.95 \%$. A greater proportion of the treatment sum of squares for plant height at first branching was due to genotype effect $(51.34 \%)$ followed by environment effect $(33.38 \%)$ and interaction effect (15.27\%). The first two interaction principal component axes accounted for a total of $79.42 \%$.

Genotype effects accounted for $53.99 \%$ of the treatment sum of squares for cassava mosaic disease severity score whilst environment and interaction effects accounted for $21.20 \%$ and $24.81 \%$, respectively. The IPCA1 accounted for $85.80 \%$ of the interaction sum of squares with IPCA2 accounting for $10.93 \%$. For storage root yield, environment effect $(37.55 \%)$ contributed a greater proportion of the treatment sum of squares compared with genotype effect $(32.77 \%)$ and genotype $*$ environment interaction $(29.68 \%)$. The first two interaction principal component axes (IPCA1 and IPCA2) accounted for $65.55 \%$ and $31.12 \%$ of the interaction sum of squares respectively. The influence of genotype $(54.10 \%)$ on root dry matter content was greater than both genotype $*$ environment interaction $(36.10 \%)$ and environment effect $(9.78 \%)$. Genotype effect $(46.22 \%)$ on harvest index was greater than the effect of interaction $(28.38 \%)$ and environment $(25.39 \%)$. The first two principal component axes contributed a total of $91.13 \%$ of the interaction sum of squares.

A large proportion of the phenotypic variance $\left(\sigma_{p}^{2}\right)$ for plant height was accounted for by the genotypic variance 


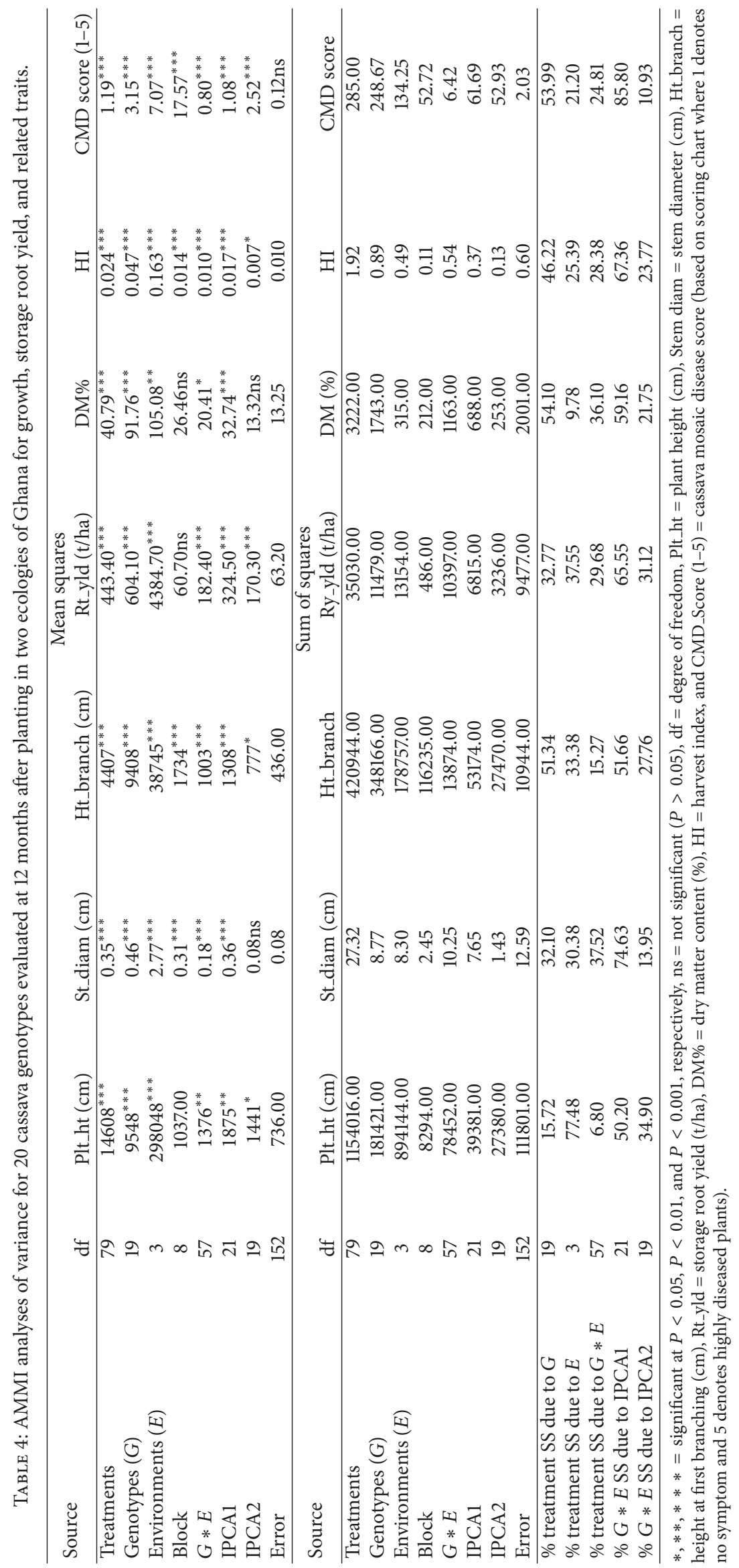


TABLE 5: Estimates of variance components, broad sense heritability, PCV, and GCV for six traits in 20 cassava genotypes from four environments.

\begin{tabular}{|c|c|c|c|c|c|c|}
\hline \multirow{2}{*}{ Parameter } & \multicolumn{6}{|c|}{ Traits } \\
\hline & Plt_ht $(\mathrm{cm})$ & Ht_branch $(\mathrm{cm})$ & St_diam (cm) & Rt_yld (t/ha) & $\mathrm{HI}$ & $\mathrm{DM}(\%)$ \\
\hline$\sigma_{g}^{2}$ & 746.98 & 630.94 & 0.013 & 24.85 & 0.003 & 4.90 \\
\hline$\sigma_{g * e}^{2^{y}}$ & 72.47 & 111.68 & 0.012 & 6.07 & 0.001 & 2.38 \\
\hline$\sigma_{e}^{2}$ & 843.90 & 387.10 & 0.091 & 45.08 & 0.004 & 13.27 \\
\hline$\sigma_{p}^{2}$ & 901.67 & 805.59 & 0.031 & 47.66 & 0.004 & 6.30 \\
\hline$H_{b}^{2}$ & 82.84 & 78.32 & 43.08 & 43.46 & 71.66 & 77.7 \\
\hline GCV (P) & 14.75 & 36.19 & 5.14 & 18.36 & 9.79 & 6.53 \\
\hline PCV (G) & 15.70 & 38.89 & 7.06 & 21.93 & 10.81 & 7.46 \\
\hline $\mathrm{P}-\mathrm{G}$ & 0.95 & 2.70 & 1.92 & 3.57 & 1.02 & 0.93 \\
\hline GA & 51.25 & 45.79 & 0.16 & 6.77 & 0.10 & 4.02 \\
\hline GAM & 27.66 & 65.98 & 6.94 & 27.31 & 17.06 & 11.86 \\
\hline
\end{tabular}

$\sigma_{g}^{2}=$ genotypic variance, $\sigma_{g * e}^{2}=$ genotype $*$ environment variance, $\sigma_{e}^{2}=$ error variance, $\sigma_{p}^{2}=$ phenotypic variance, $H_{b}^{2}=$ broad sense heritability, $\mathrm{GCV}=$ genotypic coefficient of variation (\%), PCV = phenotypic coefficient of variation (\%), GA = genetic advance, GAM = genetic advance as percentage of the mean, Plt_ht $=$ plant height $(\mathrm{cm}), H_{-}$branch $=$plant height at first branching $(\mathrm{cm})$, St_diam $=$ stem diameter $(\mathrm{cm})$, Rt_yld $=$ root yield $(\mathrm{t} / \mathrm{ha}), \mathrm{DM} \%=$ storage root dry matter content (\%), and $\mathrm{HI}=$ harvest index.

$\left(\sigma_{g}^{2}\right)$ (Table 5). Genotypic variances $\left(\sigma_{g}^{2}\right)$ for plant height and height at first branching were higher than the $G * E$ variance $\left(\sigma_{g * e}^{2}\right)$. Storage root yield and dry matter content were mostly influenced by their $\sigma_{g}^{2}$ compared with $\sigma_{g * e}^{2}$. Error variances $\left(\sigma_{e}^{2}\right)$ for all traits were higher than their phenotypic variances $\left(\sigma_{p}^{2}\right)$ except for plant height, height at branching, storage root yield, and harvest index.

The estimates of broad sense heritability varied for all the traits and were especially low for stem diameter (43.08\%) and root yield (43.46\%) (Table 5). Relatively high broad sense heritability estimates were observed for plant height (82.84\%), height at first branching (78.32\%), and storage root dry matter content (77.70\%). Phenotypic coefficient of variation for all traits was higher than the corresponding genotypic coefficient of variation (GCV). Wide differences between PCV and GCV were observed for height at branching and storage root yield. PCV ranged from $7.06 \%$ to $38.89 \%$ for stem diameter and height at first branching respectively. GCV varied from $5.14 \%$ (stem diameter) to $36.19 \%$ (height at first branching). Moderate PCVs (10-20) were observed for plant height and harvest index whereas high PCV (>20) was recorded for height at first branching. Stem diameter and root dry matter content had the lowest PCVs $(<10)$. The analysis of the expected genetic advance as percentage of the mean (GAM) indicated that height at first branching could be improved by $65.98 \%$ whilst only $6.49 \%$ progress could be made in the improvement of stem diameter. Root yield could also be improved by $27.31 \%$ whilst progress of 17.06 and $11.86 \%$ could be made in harvest index and dry matter content, respectively.

The mean performance of all genotypes across the six environments showed significant $(P<0.05)$ genetic variability for plant height, height at branching, and cassava mosaic disease severity score (Table 6). CTSIA 65 had the highest plant height $(249.67 \mathrm{~cm})$ with genotype 00/0203 having the shortest plants across all environments. The lowest height at branching genotype was I91934 $(36.38 \mathrm{~cm})$ whilst CTSIA 65 had the highest $(136.65 \mathrm{~cm})$. Average stem diameter ranged from $1.84 \mathrm{~cm}$ (CTSIA 72) to $2.61 \mathrm{~cm}(96 / 409)$. Cassava mosaic disease scores varied significantly among the different genotypes (Table 6). MM96/1751 and 00/0203 had the lowest overall mean CMD severity score (1.00) whilst CTSIA 230 had the highest. (3.13). Average root yield for all genotypes across the four environments was $24.79 \mathrm{t} / \mathrm{ha}$ (Table 5). UCC2001/449 had the highest overall root yield of $35.97 \mathrm{t} / \mathrm{ha}$ with CTSIA 48 having the lowest root yield (11.87 t/ha). Three genotypes (UCC2001/449, MM96/1751, and 96/1708) had significantly higher root yields than the best farmer preferred variety, Pontisange, whilst four genotypes had significantly better root yield than the second best farmer preferred variety, Biabasse. Harvest index also varied from 0.43 (CTSIA 110) to 0.66 (00/0203 and MM96/1751). The average harvest index for all genotypes across environments was 0.56 . Storage root dry matter ranged between $28.24 \%$ (I91934) and 38.99\% (CTSIA 110 ) with an average of $32.38 \%$.

Additive main effect and multiplicative interaction (AMMI) stability value (ASV) ranked the genotypes based on the least score (Table 7). Low scores represent the most stable genotypes. Based on the ASV, the most stable genotype for root yield was ATR 007 since it had the highest ASV ranking. 96/1708 was ranked the least stable because it had the highest ASV. In terms of root yield UCC2001/449 had the highest rank with CTSIA 48 being ranked the least. The sum of the yield and stability rankings (YSI) ranked MMM96/1751 as the genotype that combined high yield with stability. 96/1708 though high yielding was unstable because of its low rank according to the YSI. Three genotypes MMM96/1751, 00/0203, and UCC2001/449 can be considered as high yielding and stable.

Additive main effect and multiplicative interaction analysis identified four highest yielding genotypes in each of the four environments (Table 8). Four genotypes 96/1708, UCC2001/449, TME 419, and I91934 were selected for the high potential environment, Fumesua 2014. In environment FUM13, MM96/1751, UCC2001/449, 00/0203, and 
TABLE 6: Mean performance of 20 cassava genotypes evaluated in four environments.

\begin{tabular}{|c|c|c|c|c|c|c|c|}
\hline Genotypes & Plt_ht $(\mathrm{cm})$ & Ht_branch $(\mathrm{cm})$ & St_diam $(\mathrm{cm})$ & CMD (1-5) & Rt_yld (t/ha) & $\mathrm{HI}$ & DM (\%) \\
\hline $00 / 0203$ & 137.73 & 35.38 & 2.33 & 1.00 & 31.29 & 0.66 & 31.71 \\
\hline $96 / 1708$ & 142.52 & 75.27 & 2.22 & 1.08 & 32.95 & 0.65 & 30.78 \\
\hline $96 / 409$ & 180.88 & 58.58 & 2.61 & 1.17 & 27.69 & 0.53 & 29.80 \\
\hline ATR 002 & 160.53 & 62.17 & 2.36 & 1.15 & 22.36 & 0.61 & 36.05 \\
\hline ATR 007 & 221.98 & 77.95 & 2.16 & 1.48 & 24.29 & 0.53 & 35.06 \\
\hline Biabasse & 158.42 & 69.87 & 2.14 & 2.58 & 24.32 & 0.59 & 29.87 \\
\hline CTSIA 110 & 214.08 & 46.58 & 2.39 & 2.33 & 16.41 & 0.43 & 38.99 \\
\hline CTSIA 112 & 203.43 & 55.30 & 2.40 & 2.54 & 21.25 & 0.54 & 33.32 \\
\hline CTSIA 230 & 191.73 & 45.72 & 2.14 & 3.13 & 13.52 & 0.47 & 31.01 \\
\hline CTSIA 45 & 174.40 & 48.95 & 2.30 & 2.17 & 21.15 & 0.55 & 36.05 \\
\hline CTSIA 48 & 157.05 & 57.93 & 2.21 & 2.75 & 11.87 & 0.52 & 33.37 \\
\hline CTSIA 65 & 249.67 & 136.65 & 2.01 & 2.75 & 12.38 & 0.47 & 31.78 \\
\hline CTSIA 72 & 211.65 & 110.83 & 1.84 & 2.75 & 14.17 & 0.59 & 34.40 \\
\hline I91934 & 146.37 & 36.38 & 2.13 & 1.25 & 27.94 & 0.60 & 28.24 \\
\hline MM96/1751 & 190.92 & 75.80 & 2.32 & 1.00 & 32.43 & 0.66 & 29.25 \\
\hline NWA 004 & 200.22 & 69.47 & 2.15 & 1.23 & 22.97 & 0.54 & 34.49 \\
\hline Pontisange & 202.22 & 115.20 & 2.19 & 2.58 & 25.77 & 0.57 & 30.94 \\
\hline TME 419 & 199.12 & 89.42 & 2.34 & 1.10 & 26.53 & 0.56 & 31.38 \\
\hline TME 435 & 188.97 & 79.95 & 2.33 & 1.10 & 26.60 & 0.59 & 31.69 \\
\hline UCC 2001/449 & 173.37 & 41.03 & 2.52 & 1.33 & 35.97 & 0.59 & 29.45 \\
\hline Mean & 185.26 & 69.42 & 2.25 & 1.82 & 23.59 & 0.56 & 32.38 \\
\hline SED & 9.68 & 6.56 & 0.10 & 0.38 & 3.20 & 0.02 & 3.05 \\
\hline
\end{tabular}

Plt_ht $(\mathrm{cm})=$ plant height $(\mathrm{cm})$, Ht_branch $(\mathrm{cm})=$ height at first branching, CMD $(1-5)=$ cassava mosaic disease score $(1-5$ scale $)$ where 1 denotes no symptom and 5 denotes highly diseased plant, and $\mathrm{HI}=$ harvest index.

TABLE 7: Ranking of 20 cassava genotypes based on storage root yield, AMMI stability value (ASV), and yield stability index (YSI) at 12 months after planting.

\begin{tabular}{|c|c|c|c|c|c|c|c|c|}
\hline \multirow[b]{2}{*}{ Genotype } & \multicolumn{8}{|c|}{ Fresh storage root yield $(\mathrm{t} / \mathrm{ha})$} \\
\hline & Mean & $\operatorname{Rank}(\mathrm{A})$ & IPCA[1] & IPCA[2] & ASV & ASV rank (B) & YSI $(A+B)$ & YSI rank \\
\hline MM96/1751 & 32.43 & 3 & 0.45 & -2.26 & 0.54 & 4 & 7 & 1 \\
\hline Pontisange & 25.76 & 9 & -0.31 & -1.43 & 0.37 & 2 & 11 & 2 \\
\hline $00 / 0203$ & 31.29 & 4 & -1.10 & -1.07 & 1.33 & 8 & 12 & 3 \\
\hline ATR 007 & 24.29 & 11 & 0.25 & -1.54 & 0.31 & 1 & 12 & 4 \\
\hline UCC $2001 / 449$ & 35.97 & 1 & -1.48 & -1.90 & 1.78 & 11 & 12 & 5 \\
\hline Biabasse & 24.32 & 10 & 0.42 & -1.88 & 0.50 & 3 & 13 & 6 \\
\hline $96 / 409$ & 27.69 & 6 & -1.18 & -0.03 & 1.42 & 9 & 15 & 7 \\
\hline TME 435 & 26.60 & 7 & -1.19 & 0.66 & 1.44 & 10 & 17 & 8 \\
\hline I91934 & 27.94 & 5 & -1.71 & 1.50 & 2.06 & 13 & 18 & 9 \\
\hline ATR 002 & 22.36 & 13 & -0.49 & 0.96 & 0.59 & 6 & 19 & 10 \\
\hline NWA 004 & 22.79 & 12 & -0.80 & -0.18 & 0.96 & 7 & 19 & 11 \\
\hline CTSIA 110 & 16.41 & 16 & 0.45 & 2.10 & 0.54 & 5 & 21 & 12 \\
\hline $96 / 1708$ & 32.99 & 2 & -2.91 & 0.95 & 3.51 & 20 & 22 & 13 \\
\hline TME 419 & 26.53 & 8 & -2.21 & 1.12 & 2.66 & 19 & 27 & 14 \\
\hline CTSIA 45 & 21.15 & 15 & 2.01 & -0.74 & 2.42 & 14 & 29 & 15 \\
\hline CTSIA 112 & 21.24 & 14 & 2.06 & -0.18 & 2.48 & 16 & 30 & 16 \\
\hline CTSIA 65 & 12.38 & 19 & 1.48 & 0.88 & 1.78 & 12 & 31 & 17 \\
\hline CTSIA 230 & 13.52 & 18 & 2.04 & 1.54 & 2.45 & 15 & 33 & 18 \\
\hline CTSIA 72 & 14.17 & 17 & 2.09 & 0.66 & 2.52 & 17 & 34 & 19 \\
\hline CTSIA 48 & 11.87 & 20 & 2.13 & 0.83 & 2.57 & 18 & 38 & 20 \\
\hline
\end{tabular}

Rt_yld = storage root yield (t/ha), IPCA [1] score $=$ interaction principal component axis one score, IPCA [2] score = interaction principal component axis two score, ASV = AMMI stability value, and YSI = yield stability index. 
TABLE 8: First four AMMI selections based on best root yielding genotype in each environment.

\begin{tabular}{|c|c|c|c|c|c|c|}
\hline \multirow{2}{*}{ Environment } & \multirow{2}{*}{ Mean storageroot yield ( $\mathrm{t} / \mathrm{ha}$ ) } & \multirow{2}{*}{ Effect } & \multicolumn{4}{|c|}{ Rank } \\
\hline & & & 1 & 2 & 3 & 4 \\
\hline FUM14 & 34.82 & 6.283 & $96 / 1708$ & UCC2001/449 & TME419 & I91934 \\
\hline FUM13 & 25.62 & -0.732 & MM96/1751 & UCC2001/449 & $00 / 0203$ & Biabasse \\
\hline NIR13 & 17.56 & -1.481 & 96/1708 & $00 / 0203$ & MM96/1751 & TME 435 \\
\hline NIR14 & 16.34 & -1.989 & I91934 & UCC2001/449 & $96 / 1708$ & MM96/1751 \\
\hline
\end{tabular}

Biabasse were selected as the top genotypes. The top four genotypes in Nyankpala 2013 were 96/1708, 00/0203, MM96/1751, and TME 435. In the least favourable environment (Nyankpala 2014), genotypes I91934, UCC2001/449, 96/1708, and MM96/1751 were selected.

\section{Discussion}

The performance of cassava is subject to strong influence of genotype, environment, and genotype * environment interaction [10-12, 16]. Significant genotypic variations were observed for growth parameters such as plant height, stem diameter, and height at first branching indicating opportunity for selection. Similar variations in response to cassava to different environments have been reported [9, 12, 35]. Fresh root yield was significantly affected by genotype and the growing environments with much higher root yields being obtained at Fumesua than Nyankpala in both years probably due to the favourable environmental conditions typical of forest agroecologies compared with the guinea savannah ecologies. This indicates that cassava responds favourably to better environments. Similar observations were made by Turyagyenda et al. [4] and Okogbenin and Fregene [9] who observed higher yields under optimum conditions than under limited moisture. Genotype * environment interaction was observed over the different environments as indicated by crossover performances for some of the genotypes. This led to variations in the mean ranks of the genotypes in the different environments $[8,36]$. This implies different adaptation by the different genotypes suggesting the need to identify and select location specific genotypes for different environments. Alternatively yield stability analysis can be performed to identify genotypes whose performance remains stable over several years and environments [35]. In this study, genotypes performed better in the optimum environments than under stress conditions.

Harvest index was higher in the stress environments than in the humid environments (Fumesua in 2013 and 2014). Okogbenin and Fregene [9] reported higher harvest index under limited moisture conditions than under optimum conditions. This was possibly due to the tendency of cassava to grow more vigorously and produce more above ground biomass relative to their root growth in such environments $[3,37]$. This could be attributed to differential partitioning of dry matter into the above ground parts and storage roots [1,37]. Genotype CTSIA 65 had the tallest plants but had the lowest root yield suggesting that dry matter partitioning was probably directed to top growth instead of storage root bulking. Okogbenin and Fregene [9] stated that certain cassava genotypes allocate initial dry matter production for shoot growth before storage root development commences. Genotypes that are able to balance initial dry matter accumulation between shoot and root would be ideal for moisture limited environments.

Genotypic variance accounted for a large proportion of the observed phenotypic variance for $\mathrm{HI}$ and plant height indicating inherent genetic variation for these traits [38]. On the contrary, Tewodros et al. [39] found lower genotypic variances for these traits indicating strong environmental influences. Though estimates of genetic components indicated large genotypic variance $\left(\sigma^{2}{ }_{g}\right)$ for a number of traits, their error variances were higher than the phenotypic variances in most cases implying strong environmental influence. Progress in their improvement requires evaluation in several environments to minimise the effect of $G * E$ interactions that may influence progress through selection [17]. Root yield and dry matter content were influenced more by their genotypic variances than the $G * E$ interaction variances $\left(\sigma_{g * e}^{2}\right)$. This indicates the presence of a significant genetic potential and therefore provides opportunity remarkable improvement with selection. Similar observations were made by Ntawuruhunga and Dixon [16] who observed large environmental variance for fresh root yield in cassava.

Broad sense heritability estimates for dry matter content and plant height were similar to the findings of Ntawuruhunga and Dixon [16]. Heritability estimates influence the amount of progress that can be made in selection for a trait of interest [40]. However, broad sense heritability alone does not always give a full indication of genetic gain that can be made through selection since it includes both additive and nonadditive components of the variation [41, 42]. It is necessary to estimate the genetic advance as a percentage of the mean to determine the actual progress. When the genetic advance as a percentage of the mean was estimated, it was found that though storage root yield had a relatively low heritability $(43 \%)$ compared with plant height (82\%), they had the same almost the same GAM. This suggests that plant height had greater nonadditive variance and environmental influence compared with storage root yield [41].

Stability analysis methods are often used by breeders to identify genotypes that have stable performance and respond positively to improvements in environmental conditions [24]. AMMI stability value (ASV) indicates the stability of genotypes. Genotypes having low ASV are considered more stable whilst those with high values are less stable genotypes [22]. CTSIA 110, MM96/1751, and TME 435 were the most 
stable for root yield. Stability alone for yield performance does not warrant selection since a consistently low yielding genotype can still be stable [43]. In some cases the most stable genotypes do not always have the best yield performance [44]. Therefore, high root yield is considered with stability in the estimation of yield stability index (YSI). The YSI which is similar to genotype stability index (GSI) proposed by Fardshadfar [26] integrates both yield and stability across environments into a single index, to select varieties. The YSI sums the rank of mean yield across environments with the rank of the ASV of genotypes [25, 27]. Genotypes with lower YSI are desirable since they combine high mean yield performance with stability [24, 25, 27, 34]. Based on the YSI, genotypes MM96/1751, Pontisange, 00/0203, ATR 007, and UCC2001/449 were selected as combining high yield performance with stability. Genotypes such as 96/409, TME 435, and 191934 had intermediate yields with moderate stability. However genotypes 96/1708 and TME 419, although high yielding, had high ASV scores resulting in high YSI scores. However they can be recommended for specific environments where they performed well. The range of variation in the favourable environments (Fumesua 2013 and 2014) was larger than in the poor environments indicating that genotypes were better able to exploit their full potential yield in the good environments [15].

\section{Conclusion}

Genotype * environment interaction was significant for most of the traits indicating the need to test the genotypes in multiple environments before effective selection can be made. The high broad sense heritability estimates obtained for plant height and height at first branching suggest that significant progress can be made through selection for improvement of genotypes for these traits. Six genotypes (UCC2001/449, 96/1708, MM96/1751, 00/0203, 96/409, and 191934) had significantly higher root yield than the best local farmer preferred genotype, Pontisange. These genotypes can be evaluated in more environments to assess their adaptability and possible recommendation for release to farmers for cultivation.

\section{Conflicts of Interest}

The authors declare no conflicts of interest regarding the publication of this paper.

\section{Acknowledgments}

The authors are grateful to the Generation Challenge Programme and the Alliance for Green Revolution in Africa for sponsoring this study. The staff of the Root and Tuber Crops Improvement Sections of the CSIR-Savanna Agricultural Research Institute, Nyankpala, and the CSIR-Crops Research Institute are also deeply acknowledged for their efforts and assistance during the study period.

\section{References}

[1] M. A. El-Sharkawy, "Cassava biology and physiology," Plant molecular biology, vol. 56, no. 4, pp. 481-501, 2004.

[2] O. O. Aina, A. G. O. Dixon, and E. A. Akinrinde, "Effect of soil moisture stress on growth and yield of cassava in Nigeria," Pakistan Journal of Biological Sciences, vol. 10, no. 18, pp. 30853090, 2007

[3] M. A. El-Sharkawy, "Physiological characteristics of cassava tolerance to prolonged drought in the tropics: Implications for breeding cultivars adapted to seasonally dry and semiarid environments," Brazilian Journal of Plant Physiology, vol. 19, no. 4, pp. 257-286, 2007.

[4] L. F. Turyagyenda, E. B. Kizito, M. Ferguson et al., "Evaluation of Ugandan cassava germplasm for drought tolerance," International Journal of Agriculture and Crop Science, vol. 5, no. 3, pp. 212-226, 2013.

[5] P. C. Haldavankar, G. D. Joshi, S. G. Bhave, R. G. Klandekar, and S. S. Sawant, "Stability of yield and yield attributing phenotypic characters in sweet potato," Journal of Root Crops, vol. 35, no. 1, pp. 28-35, 2009.

[6] J. Crossa and P. L. Cornelius, "Sites regression and shifted multiplicative model clustering of cultivar trial sites under heterogeneity of error variances," Crop Science, vol. 37, no. 2, pp. 406-415, 1997.

[7] J. Mkumbira, N. M. Mahungu, and U. Gullberg, "Grouping locations for efficient cassava evaluation in Malawi," Experimental Agriculture, vol. 39, no. 2, pp. 167-179, 2003.

[8] A. G. Dixon and E. N. Nukenine, "Genotype * environment interaction and optimum resource allocation for yield and yield components of cassava," African Crop Science Journal, vol. 8, no. 1, pp. 1-10, 2000.

[9] E. Okogbenin and M. Fregene, "Genetic analysis and QTL mapping of early root bulking in an F1 population of non-inbred parents in cassava (Manihot esculenta Crantz)," Theoretical and Applied Genetics, vol. 106, no. 1, pp. 58-66, 2002.

[10] O. O. Aina, A. G. O. Dixon, and E. A. Akinrinde, "Trait association and path analysis for cassava genotypes in four agroecological zones of Nigeria," Journal of Biological Sciences, vol. 7, no. 5, pp. 759-764, 2007.

[11] C. N. Egesi, P. Ilona, F. O. Ogbe, M. Akoroda, and A. Dixon, "Genetic variation and genotype * environment interaction for yield and other agronomic traits in cassava in Nigeria," Agronomy Journal, vol. 99, no. 4, pp. 1137-1142, 2007.

[12] O. O. Aina, A. G. O. Dixon, P. Illona, and E. A. Akinrinde, "G ${ }^{*}$ E interaction effects on yield and yield components of cassava (landraces and improved) genotypes in the savannah regions of Nigeria," African Journal of Biotechnology, vol. 8, no. 19, pp. 4933-4945, 2009.

[13] D. S. Falconer and T. F. C. Mackay, Introduction to Quantitative Genetics, Longman, New York, NY, USA, 1996.

[14] G. Ssemakula and A. G. O. Dixon, "Genotype * environment interaction, stability and agronomic performance of carotenoid-rich cassava clones," Scientific Research and Essays, vol. 2, no. 9, pp. 390-399, 2007.

[15] M. Przystalski, A. Osman, E. M. Thiemt et al., "Comparing the performance of cereal varieties in organic and non-organic cropping systems in different European countries," Euphytica, vol. 163, no. 3, pp. 417-433, 2008.

[16] P. Ntawuruhunga and A. G. O. Dixon, "Quantitative variation and interrelationship between factors influencing cassava yield," Journal of Applied Biosciences, vol. 26, pp. 1594-1602, 2010. 
[17] E. Otoo, C. R. Okonkwo, and R. Asiedu, "Stability studies of hybrid yam genotypes in Ghana," Journal of Food, Agriculture and Environment, vol. 4, no. 1, pp. 234-238, 2006.

[18] S. A. Eberhart and W. A. Russell, "Stability parameters for comparing varieties," Crop Science, vol. 6, pp. 36-40, 1966.

[19] H. G. Gauch, "Model selection and validation for yield trials with interaction," Biometrics, vol. 44, no. 3, pp. 705-715, 1988.

[20] F. A. van Eeuwijk, "Linear and bilinear models for the analysis of multi-environment trials: I. An inventory of models," Euphytica, vol. 84, no. 1, pp. 1-7, 1995.

[21] R. Bernardo, Breeding for Quantitative Traits in Plants, Stemma Press, Woodbury, Minn, USA, 2010.

[22] H. G. Hagos and F. Abay, "AMMI and GGE biplot analysis of bread wheat genotypes in the northern part of Ethiopia," Journal of Plant Breeding and Genetics, vol. 1, pp. 12-18, 2013.

[23] J. L. Purchase, H. Hatting, and C. S. van Deventer, "Genotype * environment interaction of wheat in South Africa: stability analysis of yield performance," South African Journal of Plant and Soil, vol. 17, no. 3, pp. 101-107, 2000.

[24] E. Farshadfar, N. Mahmodi, and A. Yaghotipoor, "AMMI stability value and simultaneous estimation of yield and yield stability in bread wheat (Triticum aestivum L.)," Australian Journal of Crop Science, vol. 5, no. 13, pp. 1837-1844, 2011.

[25] R. Tumuhimbise, R. Melis, P. Shanahan, and R. Kawuki, “Genotype ${ }^{*}$ environment interaction effects on early fresh storage root yield and related traits in cassava," The Crop Journal, vol. 2, no. 5, pp. 329-337, 2014.

[26] E. Farshadfar, "Incorporation of AMMI stability value and grain yield in a single non parametric index (GSI) in bread wheat," Pakistan Journal of Biological Sciences, vol. 11, no. 14, pp. 17911796, 2008.

[27] F. Baraki, Y. Tsehaye, and F. Abay, "AMMI analysis of genotype * environment interaction and stability of sesame genotypes in Northern Ethiopia," Asian Journal of Plant Sciences, vol. 13, no. 4, pp. 178-183, 2014.

[28] EPA, "National action programme to combat drought and desertification," Environmental Protection Agency AccraGhana, 2003.

[29] I. J. Ekanayake, “Cassava procedures for growth analysis," IITA Procedures Manual, 24 pages, 1996.

[30] W. Msikita, B. James, E. Nnodu, J. Legg, K. Wydra, and F. Ogbe, Disease Control in Cassava Farms: IPM Field Guide for Extension Agents, IITA publication, 2000.

[31] R. W. Payne, D. A. Murray, S. A. Harding, D. B. Baird, and D. M. Soutar, Genstat for Windows: Introduction, VSN International, Hemel Hempstead, UK, 12th edition, 2009.

[32] F. K. Padi, "Genotype * environment interaction and yield stability in a cowpea-based cropping system," Euphytica, vol. 158, no. 1-2, pp. 11-25, 2007.

[33] K. Singh and B. Chaudhary, Biometrical Methods in Quantitative Genetic Analysis, Kalyani publishers/Lyall Bk Depot, 1979.

[34] L. K. Bose, N. N. Jambhulkar, K. Pande, and O. N. Singh, "Use of AMMI and other stability statistics in the simultaneous selection of rice genotypes for yield and stability under directseeded conditions," Chilean Journal of Agricultural Research, vol. 74, no. 1, pp. 1-9, 2014.

[35] R. W. Mutegi, Towards identifying the physiological and molecular basis of drought tolerance in cassava (Manihote sculenta Crantz) [Ph.D. thesis], Georg-August University Gottingen, 2009.
[36] M. Malosetti, J.-M. Ribaut, and F. A. van Eeuwijk, "The statistical analysis of multi-environment data: Modeling genotypeby-environment interaction and its genetic basis," Frontiers in Physiology, vol. 4, article 44, 2013.

[37] A. A. C. Alves, "Cassava Botany and Physiology," in Cassava: Biology, Production and Utilization, R. J. Hillocks, J. M. Thresh, and A. Bellotti, Eds., pp. 67-90, CABI, Wallingford, UK, 2002.

[38] E. Tsegaye, N. Dechassa, and E. V. D. Sastry, "Genetic variability for yield and other agronomic traits in sweet potato," Journal of Agronomy, vol. 6, no. 1, pp. 94-99, 2007.

[39] M. Tewodros, W. Getachew, B. Tadesse, and W. Tesfaye, "Genetic diversity of cassava (Manihot esculenta Crantz) genotypes in Ethiopia," Greener Journal of Agricultural Sciences, vol. 3, no. 9, pp. 636-642, 2013.

[40] T. Sabesan, R. Suresh, and K. Saravanan, "Genetic variability and correlation for yield and grain quality characters of rice grown in coastal saline low land of Tamil Nadu," Electronic Journal of Plant Breeding, vol. 1, pp. 56-59, 2009.

[41] T. Pradeepkumar, D. Bastian, M. Joy, N. V. Radhakrishnan, and K. C. Aipe, "Genetic variation in tomato for yield and resistance to bacterial wilt," Journal of Tropical Agriculture, vol. 39, pp. 157$158,2001$.

[42] A. K. Singh, P. Sharma, and P. K. Singh, "Studies on genetic characteristic of upland rice (Oryza sativa L.)," International Journal of Agriculture, Environment and Biotechnology, vol. 6, no. 4, pp. 515-520, 2013.

[43] W. Yan and N. A. Tinker, "Biplot analysis of multi-environment trial data: Principles and applications," Canadian Journal of Plant Science, vol. 86, no. 3, pp. 623-645, 2006.

[44] E. Oliveira and I. Godoy, "Pod yield stability analysis of runner peanut lines using AMMI," Cropp Breeding and Applied Biotechnology, vol. 6, no. 4, pp. 310-317, 2006. 


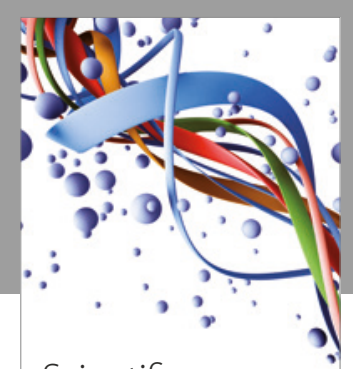

Scientifica
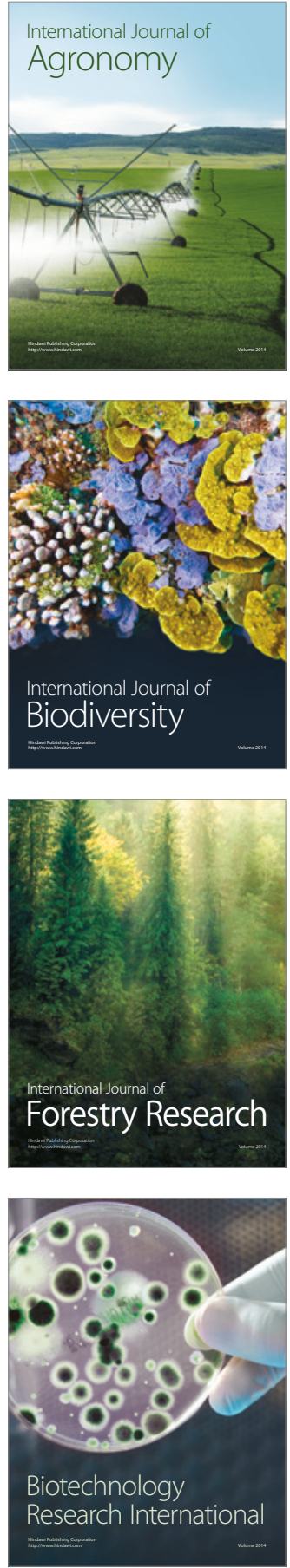
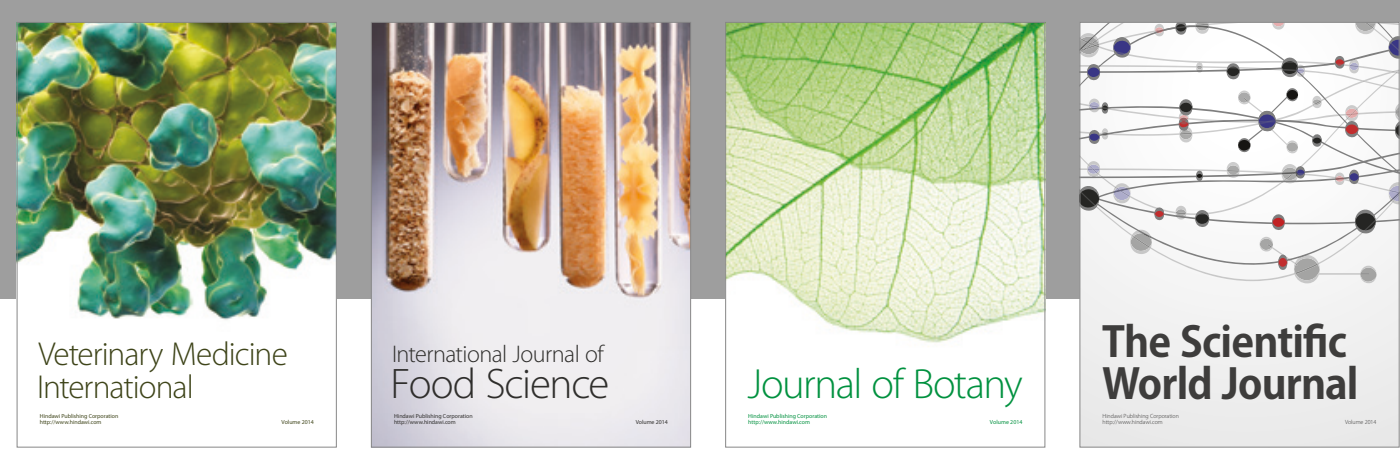

The Scientific

\section{World Journal}

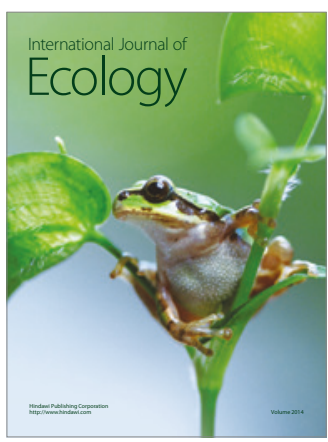

\section{Hindawi}

Submit your manuscripts at

https://www.hindawi.com
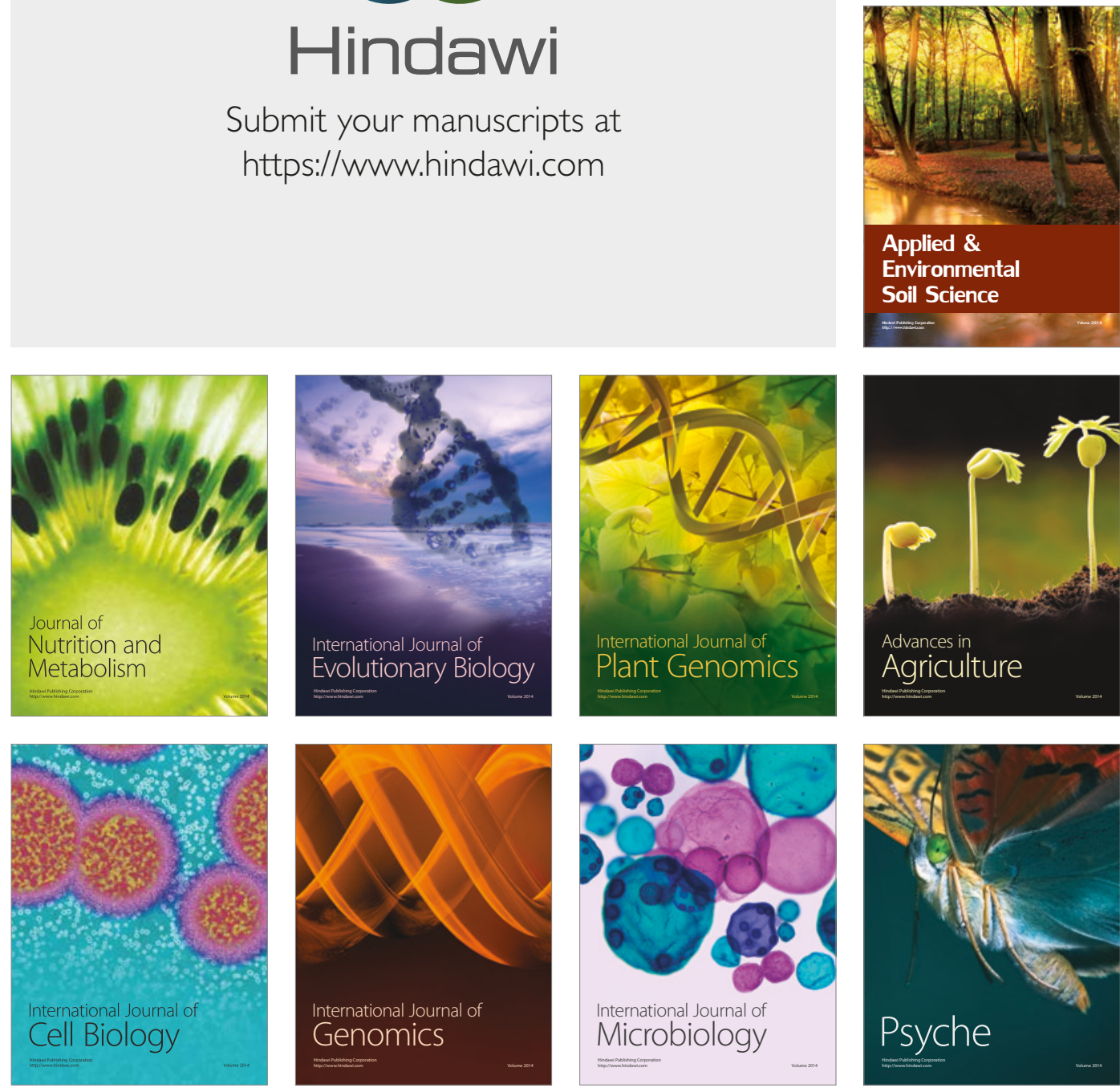

hternational Journal of Microbiology
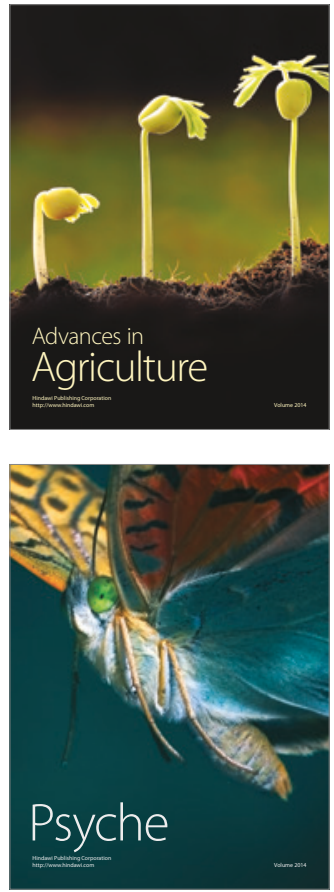